\title{
COVID Implications in Dentistry - A Questionnaire Survey
}

\section{IJCRR}

Section: Healthcare

Sci. Journal Impact

Factor: 6.1 (2018)

ICV: 90.90 (2018)

(c) (i) (8)

Copyright@IJCRR

\section{Prabhav Kumar Iyer ${ }^{1}$, Sri Rengalakshmi ${ }^{2}$, Sarvana Dinesh S. P. ${ }^{3}$}

'Saveetha Dental College, Saveetha Institute of Medical and Technical Sciences, Chennai, India; ${ }^{2}$ Senior Lecturer, Department of Orthodontics, Saveetha Dental College, Saveetha Institute of Medical and Technical Sciences, Chennai, India; 3 Professor and Head of Administration, Department of Orthodontics, Saveetha Dental College, Saveetha Institute of Medical and Technical Sciences, Chennai, India.

\section{ABSTRACT}

Introduction: COVID-19 is a zoonotic virus that originated in bats and pangolins and was later transmitted to humans. The infection began in Wuhan City, Hubei Province in China and was initially diagnosed as an acute respiratory syndrome of unknown origin. The virus has been known to spread via infected droplets, aerosols, and direct contact making it an efficient pathogen. All healthcare workers, especially dentists [since they come in contact with infected aerosol on a daily basis] are at a higher risk of infection with COVID. This study is to check the awareness of the condition among dentists and dental students and to see the effect this disease has bought on dentistry. The aim of this study is to discuss the implications of COVID in dentistry.

Materials and Methods: The study was carried out in a self-administered questionnaire format. The questionnaire was created on an online platform called Survey Planet and distributed to dental students and private practitioners. The questionnaire consisted of knowledge about COVID and steps on taking extra precautions while seeing patients. The data was collected and compiled in SPSS.

Results: Based on the tabulated data, it was seen that most dentists had good knowledge about their practice. $89 \%$ agreed that dentists are at a higher risk for COVID. $60.8 \%$ said that COVID spreads through infected aerosols. $57.1 \%$ said that they would deny treatment to a patient if they suspect them to be infected with COVID-19. $76.9 \%$ feel anxious while treating patients and $82.4 \%$ are aware of the authorities to call if they come across a patient suspected with COVID-19.

Conclusion: It is important for dentists to use proper PPE equipment like masks, face shields, and gowns. Procedures that involve the production of aerosols should be avoided until necessary. Moreover, proper sanitization should be done after completing a procedure and the chair should be disinfected with disinfectants to minimize the chances of the spread of the pathogen via aerosols. Based on the results it is seen the dentists are very anxious when it comes to treating patients during the pandemic. However, they are well aware of the dangers of this disease and are taking precautions to keep themselves and their patients safe.

Key Words: COVID, Aerosol, Infection, Sanitization, Anxiety, Dental practice

\section{INTRODUCTION}

COVID-19 is the first coronavirus to cause a pandemic. The infection started in Asia and spread all across the world. ${ }^{1}$ On the 29th of December, 2019, the first four cases of an acute respiratory syndrome of unknown origin were reported in Wuhan city, Hubei province, China. It appears that most of the early cases had some sort of contact with a seafood market. ${ }^{2}$ Initial attempts to control the spread of the virus failed which caused Wuhan to be under quarantine. The carriers travelled across the world and soon cases of COVID-19 started erupting in multiple geographic locations around the globe. The modes of transmission are through contact and in the form of droplets ${ }^{3-5}$ when this virus infects a human, the host clinically present with symptoms of fever, cough, myalgia, or fatigue, abnormal chest $\mathrm{CT}$ image, and severe respiratory distress, whereas less common symptoms include sputum production, headache, hemoptysis, and diarrhea ${ }^{6}$

Previously, we have conducted numerous clinical trials ${ }^{7-13}$ and various lab animal studies ${ }^{14-18}$ and in vitro studies ${ }^{19,20,21}$ over the past 5 years. Currently, we are focusing on epidemiological surveys. The idea for this survey stemmed from the current interest in our community.

Ever since the pandemic, the idea of flattening the curve is prevalent which means reducing the number of cases so that

\section{Corresponding Author:}

Dr. Sri Rengalakshmi, Senior Lecturer, Department of Orthodontics, Saveetha Dental College, Saveetha Institute of Medical and Technical Sciences, Chennai, India; Telephone: +918867783552; Email: srirengalakshmi.sdc@saveetha.com

ISSN: 2231-2196 (Print)

Received: 21.07 .2020
ISSN: 0975-5241 (Online)

Revised: 26.08 .2020
Accepted: 28.09 .2020
Published: 20.10 .2020 
the healthcare system of a country won't be burdened with an abundant number of cases which is more than what they can handle. This is a problem especially considering that people under emergency healthcare are constantly handling COVID patients which increases the chances of them getting infected.

Dentists have a higher chance of getting infected as dental treatments can lead to the spread of infection since the maximum number of cases of dental procedures cause aerosols generation, frequent exposure to saliva, blood and body fluids, and the handling of sharp instruments. So, to prevent the spread of the disease, dentists should prioritize paper history taking, patient education, and infection prevention measures. ${ }^{22}$

Hence, this study aims to see the implications of this disease and dentistry and to check the knowledge of dentists and dental students in regard to COVID-19.

\section{MATERIALS AND METHODS}

\section{Study Design and Setting}

A descriptive cross-sectional study was conducted in Chennai. The participants consisted of undergraduates, post-graduates, and dentists having a private practice. The questionnaire was pre-tested by dentists in Chennai.

\section{Data Collection}

An outline platform known as "Survey Planet" was used. The questionnaire was verified by an external source. The questionnaire was uploaded on www.surveyplanet.com and the link was sent to dental students and dentists across Chennai. The questionnaire can be seen in Figure 9. Data was verified by an external viewer.

\section{Statistical Analysis}

Data were recorded in Microsoft Excel 2016 (Microsoft Office 10) and later exported to the Statistical Package for Social Science for Windows (Version 20.0, SPSS Inc., Chicago, Illinois, USA). The results were analyzed and the responses were tabulated in the form of bar graphs.

\section{RESULTS AND DISCUSSION}

Out of the 273 people who filled the survey, $34.7 \%$ were undergraduate students posted in clinics. $41.7 \%$ were post-graduates and $23.4 \%$ of people ran a private practice in Chennai [Figure 1]. 89\% agreed that dentists are at a higher risk of infection [Figure 2] $(9=0.368) .60 .8 \%$ said that COVID-19 spreads through infected aerosols $(p=0.624) .14 .28 \%$ said that blood contact can cause the virus to spread. The rest $4.02 \%$ were unaware of the route transmission [Figure 3]. 57.1\% said that they would deny treatment to a COVID suspected patient [Figure 4]. The others would continue using protective gear $(p=0.012)$. $78.02 \%$ have started to use more protective equipment while treating patients [Figure 5]. 76.9\% feel more anxious while treating patients [Figure 7] $(\mathrm{p}=0.048) .76 .5 \%$ reported having less number of patients visiting them during the pandemic $(p=.0229)$. Finally, $82.4 \%$ were aware of the authorities to contact if they came across a COVID suspected patient [Figure 8] $(\mathrm{p}=0.001)$.

The emergence of newer pathogens on a daily basis poses a major threat in treating hospitalized patients. ${ }^{23}$ Many countries in the world are currently under lockdown to prevent the further spread of the virus. Emergency professionals like the police, firemen, healthcare workers, etc are allowed to come in contact with people. Thus, indeed helps in preventing a large outbreak, but it puts a particular group under higher risk. In Italy, over 13000 health care workers were affected with the death of 86 medical doctors and 8 dentists. ${ }^{24}$ Similarly, according to studies, as of February 2020, there was 18,811 confirmed cases globally with 2462 deaths in over 29 countries ${ }^{25,26}$

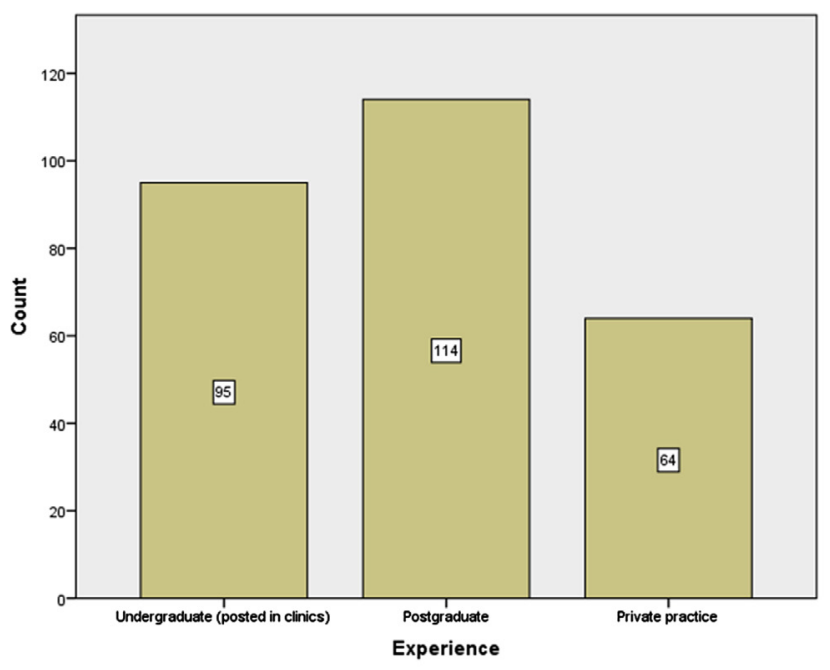

Figure 1: Bar Graph depicting the experience of the participants of the survey. The X-axis represents the experience of the participants of the study. The Y-axis represents the number of participants choosing either option. The graph depicts $41.7 \%$ of the participants are postgraduate students, $34.7 \%$ are undergraduate students, and the remaining $23.4 \%$ to be dentists running a private practice. 


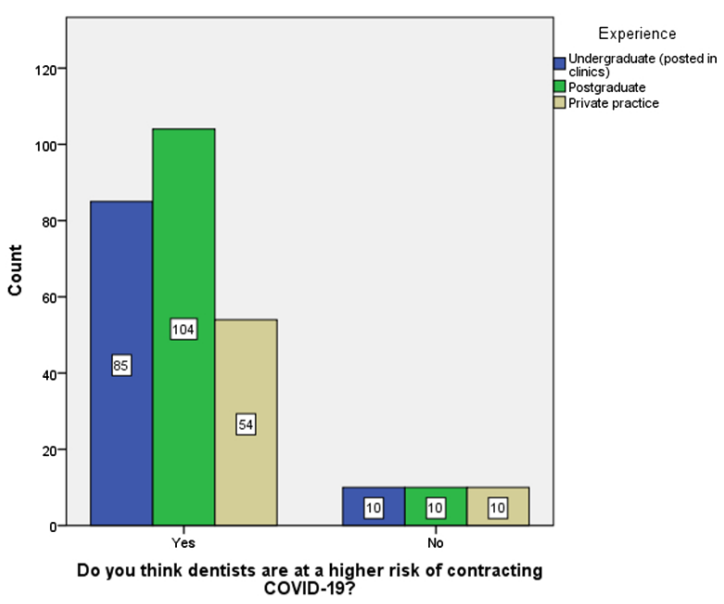

Figure 2: Bar graph depicting the response to the question: Do you think dentists are at a higher risk of contracting COVID-19? The $\mathrm{X}$-axis represents the responses to the question. The Y-axis represents the number of participants choosing either response. $89 \%$ of the respondents agreed that dentists are at a higher risk of contracting COVID-19. The remaining $11 \%$ did not believe that dentists were at a higher risk of contracting COVID-19 (which included equal numbers of the undergraduates, post-graduates, and private practitioners). The significance was tested using the Chi-square test and the significance was found to be $p=0.368$ ( $p>0.05)$, which is not statistically not significant.

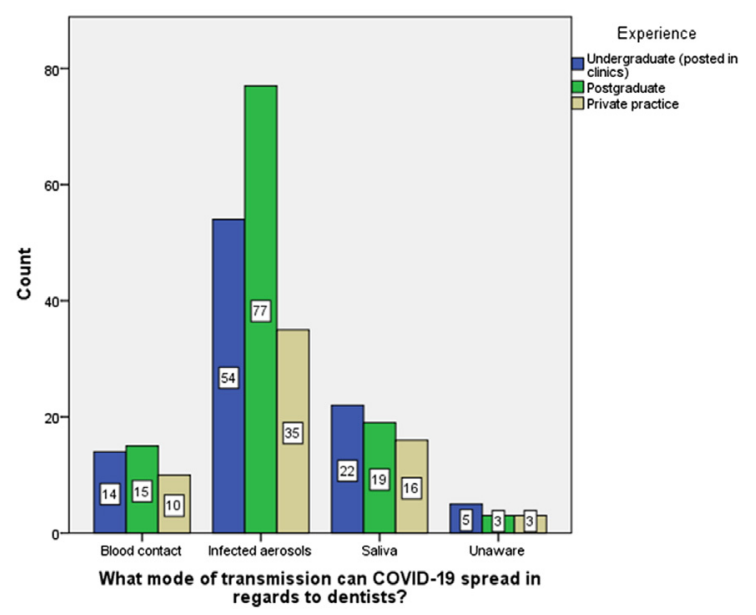

Figure 3: Bar graph depicting the response to the question: What mode of transmission can COVID-19 spread in regards to dentists? The $\mathrm{X}$-axis represents the responses to the question. The $Y$-axis represents the number of participants choosing either response. $60.8 \%$ believed COVID-19 spreads through infected aerosols, $20.8 \%$ believed it spread through saliva, $14.28 \%$ believed that it spread through contact of blood and the remaining $4.02 \%$ were unaware The significance was tested using the Chi-square test and the significance was found to be $p=0.624(p>0.05)$, which is statistically not significant.

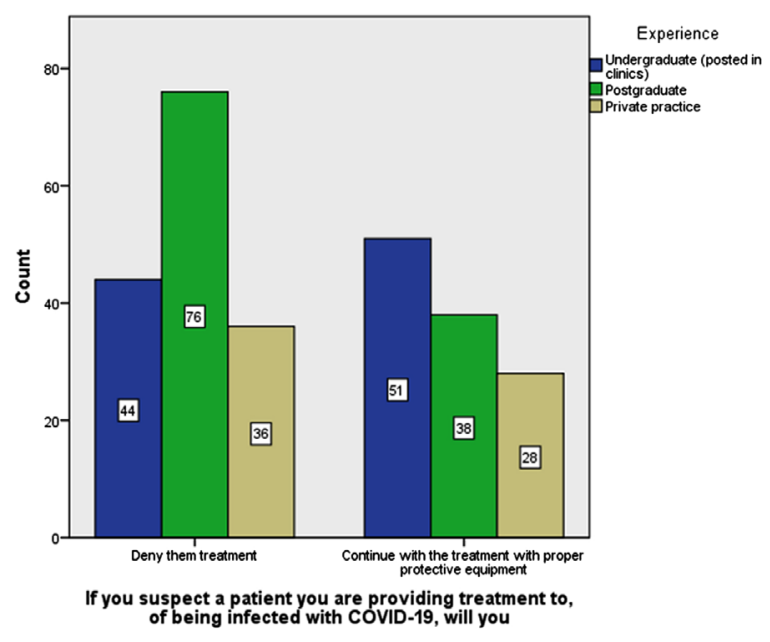

Figure 4: Bar graph depicting the response to the question: If you suspect a patient you are treating to be infected with COVID-19, will you. The X-axis represents the responses to the question. The $\mathrm{Y}$-axis represents the number of participants choosing either response. $57.1 \%$, which includes a higher frequency of post-graduates, would deny treatment to a patient if they suspected the patient to be infected with COVID-19. The remaining $42.9 \%$ would do the treatment with proper protective equipment. The significance was tested using the Chi-square test and the significance was found to be $p=0.012(p<0.05)$, which is statistically significant.

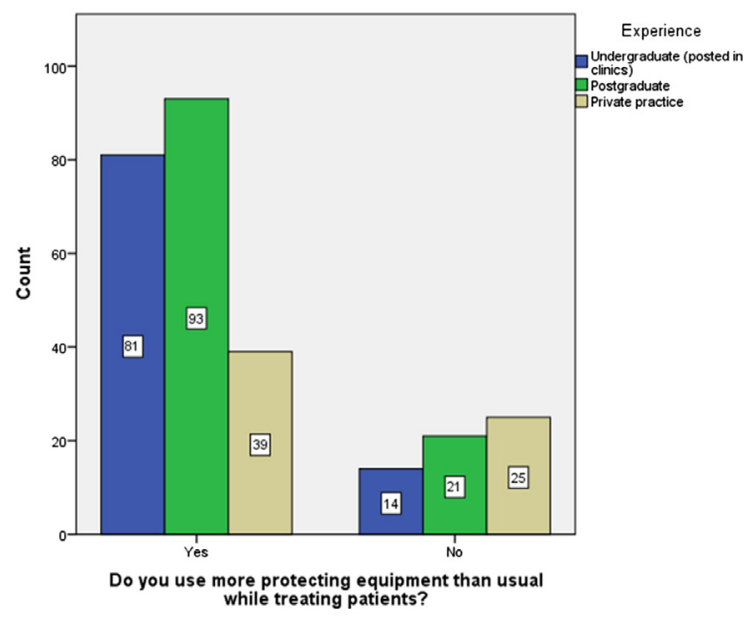

Figure 5: Bar graph depicting the response to the question: Do you use more protecting equipment than usual while treating patients? The $\mathrm{X}$-axis represents the responses to the question. The $\mathrm{Y}$-axis represents the number of participants choosing either response. $78.02 \%$ have started using more protective equipment while treating patients. 21.98 still use the same amount of protection as they have been using in the past. The significance was tested using the Chi-square test and the significance was found to be $p=0.001(p<0.05)$, which is statistically significant. 


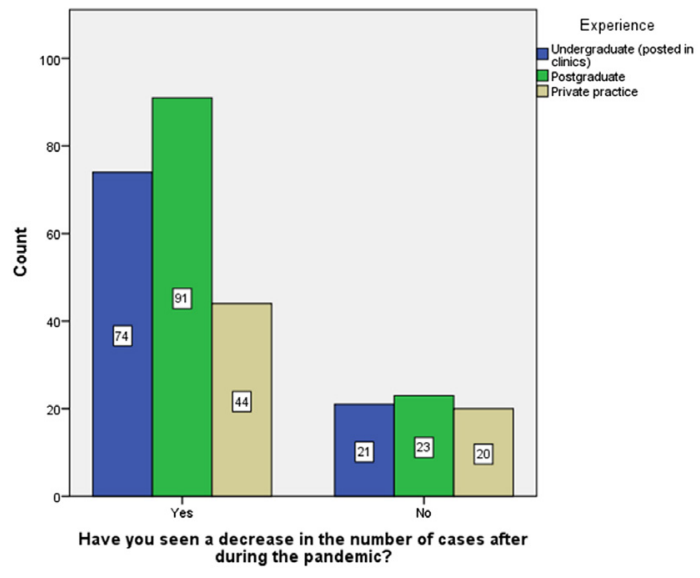

Figure 6: Bar graph depicting the response to the question: Have you seen a decrease in the number of cases after during the pandemic? The $\mathrm{X}$-axis represents the responses to the question. The $Y$-axis represents the number of participants choosing either response. $76.5 \%$ have reported seeing a decrease in the number of patients during the pandemic while $23.5 \%$ did not notice a decrease in the patient flow at their respective places of practice. The significance was tested using the Chi-square test and the significance was found to be $p=0.229$ ( $p>0.05)$, which is statistically not significant.

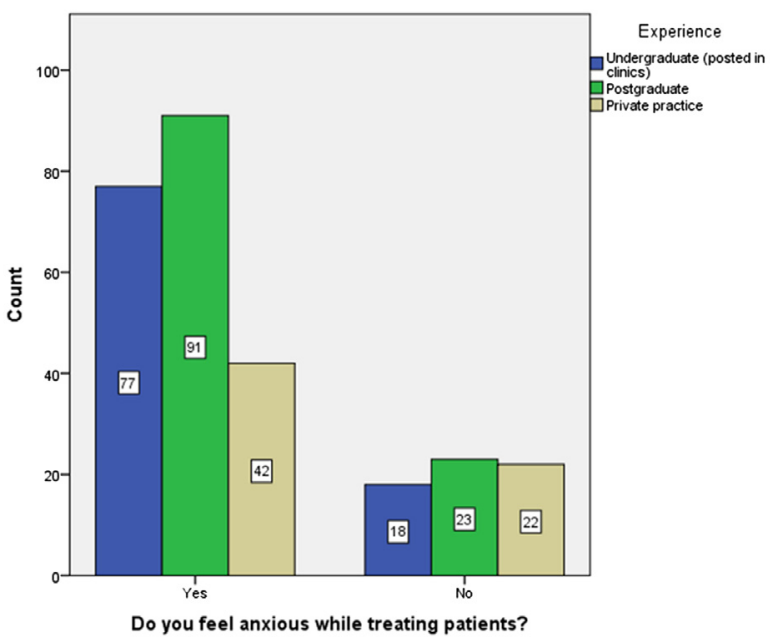

Figure 7: Bar graph depicting the response to the question: Do you feel anxious while treating patients? The $\mathrm{X}$-axis represents the responses to the question. The $Y$-axis represents the number of participants choosing either response. $76.9 \%$ reported anxiety while treating patients. $23.1 \%$ reported no such feeling while treating their patients. The significance was tested using the Chi-square test and the significance was found to be $p=0.048(p<0.05)$, which is statistically significant.

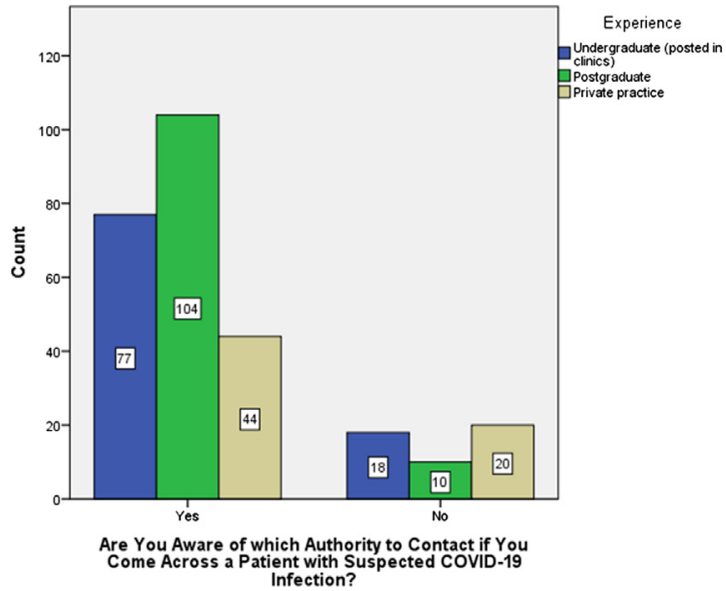

Figure 8: Bar graph depicting the response to the question: Are You Aware of which Authority to Contact if You Come Across a Patient with Suspected COVID-19 Infection? The X-axis represents the responses to the question. The $\mathrm{Y}$-axis represents the number of participants choosing either response. $82.4 \%$ of the respondents were aware of the authorities to contact in case they come across a suspected COVID-19 case. The remaining $17.6 \%$ were not aware of the contact information. The significance was tested using the Chi-square test and the significance was found to be $p=0.001(p<0.05)$, which is statistically significant.

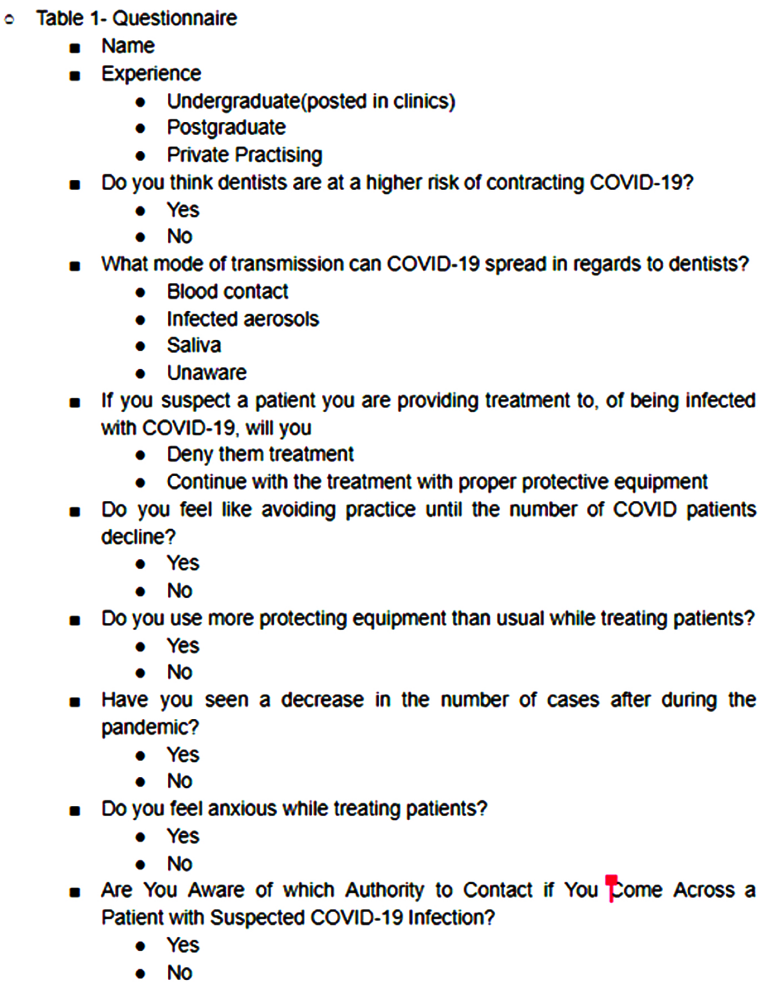

Figure 9: Image depicting the questionnaire used in this study. Orthodontic treatment with fixed appliances alters the oral 
environment, increases the plaque amount, changes the composition of the flora, and obstructs the physical removal. ${ }^{27}$ Hence, it is best to avoid any kind of orthodontic treatment during this time.

This study noted that there is a rise of fear among dentists to treat patients during the pandemic. This is in accordance with a study done by Ahmed et al. where $72 \%$ of people felt anxious talking to patients in close proximity, $66 \%$ felt like closing their practice until the number of cases started declining. ${ }^{28}$ This could be because dentists are more vulnerable towards infections spread through direct contact or vua aerosols, since their work requires them to be in close proximity to the patient during the time of diagnosis and treatment. When dental students are considered, them showing anxiety towards treatment during the earlier days of their clinical posting is shown in various studies (e.g. a study done by Kirova et al. ${ }^{29}$. A study by Guo et al. showed the proportion of dental and oral infections increased from $51.9 \%$ to $71.9 \%$. It also showed that the most frequent causes for patients visiting the emergency room are dental, pulpal or periapical lesions and cellulitis or abscess. ${ }^{4,30}$ In an article by Dominiak et al., the guidelines are given by the Polish Dental Association Working Group was mentioned as:

1. Wearing PPE's in proper order

2. Using antiseptics to deactivate the virus ${ }^{31}$

The procedures done by dentists also need to undergo certain changes during the pandemic. According to the instructions given by the DCI, any procedure involving the production of aerosol should be restricted until necessary to minimize the spread of the pathogen. Orthodontic and prosthodontic procedures (which are not urgent) are put on hold to focus on patients who need immediate relief due to pain, swelling, etc. Every dentist who is practicing during this time has to wear every part of their PPE equipment to prevent the spread of infections. While doubling down on the number of masks and gloves is not recommended due to the scarcity of these items, they should be used and disposed of safely once the procedure is completed.

Unfortunately, there is very little evidence to show mouthwashes to be effective against this organism. A study by Renuka et al. showed that chlorhexidine is useless against many kinds of viruses. ${ }^{32}$ But another study by Maricker et al showed chlorhexidine to have the greatest zone of inhibition for Enterococcus faecalis. ${ }^{33}$. A study by Girija et al. showed resistance against carbapenem by $A$. baumannii ${ }^{34,35,36}$ while another study by Vaishali et al. showed Orange peel oil to have a good antibacterial action against $S$. mutans ${ }^{37}$ Another study by Priyadarsini et al. showed that virulent genes can be used to create targets against organism ${ }^{38}$ (e.g. A study by Shahzan et al. showed kaempferol from A. nilotica showed an inhibitory effect against ERG11 of $C$. albicans ${ }^{39}$. Vaccination can be very useful against viral infections ${ }^{40}$ but currently, there are no known vaccines against COVID-19. Another method to manage such patients can be through medications to relieve the symptoms. This can be through anti-inflammatory ${ }^{41}$ and antibiotics. It is also important to switch up the drugs used regularly because the organism might develop resistance to one particular drug. ${ }^{42}$. The invention of a new drug or vaccine can be done via molecular technology ${ }^{43}$. This study could be used as a guideline and similar other studies can be made addressing this issue. It is absolutely imperative for dentists to follow proper protection guidelines to safeguard themselves, their families as well as their patients.

\section{CONCLUSION}

By the results, we can conclude that dental students and dentists had knowledge about COVID-19 and showed high amounts of anxiety when dealing with patients. This seems to be due to extreme caution taken while dealing with patients. Also, the participants use extra protective measures while dealing with any patient. COVID-19 has had a major impact on the way healthcare is delivered by medical professionals and will have an impact both physically, mentally, and economically on dental services for a few months after the pandemic is over, but if proper safety guidelines are followed, the damage can be minimized.

\section{ACKNOWLEDGMENT}

Authors acknowledge the immense help received from the scholars whose articles are cited and included in references to this manuscript. The authors are also grateful to authors / editors / publishers of all those articles, journals, and books from which the literature for this article has been reviewed and discussed.

\section{Conflict of interest}

Nil

\section{Financial Support}

The study was financed by the authors of this study.

\section{REFERENCES}

1. Spagnuolo G, De Vito D, Rengo S, Tatullo M. COVID-19 Outbreak: An Overview on Dentistry. Int J Environ Res Public Health. 2020 Mar 22;17(6):2094.

2. Krithikadatta J. Endodontic and Dental Practice during COVID-19 Pandemic: Position Statement from Indian Endodontic Society Indian Dental Association, and International Federation of Endodontic Associations. Endodontology. 2020 Jun $18 ; 32(2): 55-66$. 
3. Zhu N, Zhang D, Wang W, Li X, Yang B, Song J, et al. A Novel Coronavirus from Patients with Pneumonia in China, 2019. N Engl J Med. 2020 Feb 20;382(8):727-33.

4. Guo H, Zhou Y, Liu X, Tan J. The impact of the COVID-19 epidemic on the utilization of emergency dental services. Journal of Dental Sciences. 2020 Mar 16.

5. Li Q, Guan X, Wu P, Wang X, Zhou L, Tong Y, et al. Early Transmission Dynamics in Wuhan, China, of Novel Coronavirus-Infected Pneumonia. N Engl J Med. 2020 Mar 26;382(13):1199207.

6. Kamate SK, Sharma S, Thakar S, Srivastava D, Sengupta K, Hadi AJ, et al. Assessing Knowledge, Attitudes and Practices of dental practitioners regarding the COVID-19 pandemic: A multinational study. Dental and Medical Problems. 2020;57(1):11-7.

7. Sivamurthy G, Sundari S. Stress distribution patterns at miniimplant site during retraction and intrusion-a three-dimensional finite element study. Prog Orthod. 2016 Jan 18;17(1):4.

8. Samantha C, Sundari S, Chandrasekhar S, Sivamurty G, Dinesh S. Comparative evaluation of two Bis-GMA based orthodontic bonding adhesives-A randomized clinical trial. J Clin Diagn Res. 2017;11(4):ZC40.

9. Krishnan S, Saravana Pandian AKS. Effect of bisphosphonates on orthodontic tooth movement-an update. J Clin Diagn Res. 2015;9(4):ZE01.

10. Vikram NR, Prabhakar R, Kumar SA, Karthikeyan MK, Saravanan R. Ball Headed Mini Implant. J Clin Diagn Res. 2017;11(1):ZL02.

11. Kamisetty SK, Verma JK, Arun SS, Chandrasekhar S, Kumar A. SBS vs Inhouse Recycling Methods-An Invitro Evaluation. J Clin Diagn Res. 2015;9(9):ZC04.

12. Viswanath A, Ramamurthy J, Dinesh SPS, Srinivas A. Obstructive sleep apnea: Awakening the hidden truth. Niger J Clin Pract. 2015 Jan 19;18(1):1-7.

13. Felicita AS. Quantification of intrusive/retraction force and moment generated during en-masse retraction of maxillary anterior teeth using mini-implants: A conceptual approach. Dental Press J Orthod. 2017;22(5):47-55.

14. Rubika J, Felicita AS, Sivambiga V. Gonial angle as an indicator for the prediction of growth pattern. World J Dent. 2015;6(3):161-3.

15. Jain RK, Kumar SP, Manjula WS. Comparison of intrusion effects on maxillary incisors among mini implant anchorage, $\mathrm{j}$-hook headgear and utility arch. J Clin Diagn Res. 2014;8(7):ZC21.

16. Saravana Pandian K, Krishnan S, Aravind Kumar S. Angular photogrammetric analysis of the soft-tissue facial profile of Indian adults. Indian J Dent Res. 2018 Mar 1;29(2):137.

17. Ramesh Kumar KR, Shanta Sundari KK, Venkatesan A, Chandrasekar S. Depth of resin penetration into enamel with 3 types of enamel conditioning methods: A confocal microscopic study. Am J Orthod Dentofacial Orthop. 2011 Oct 1;140(4):479-85.

18. Felicita AS. Orthodontic management of a dilacerated central incisor and partially impacted canine with unilateral extraction--A case report. The Saudi dental journal. 2017;29(4):185-93.

19. Felicita AS, Chandrasekar S, Shanthasundari KK. Determination of craniofacial relation among the subethnic Indian population: A modified approach-(Sagittal relation). Indian J Dent Res. 2012;23(3):305.

20. Dinesh SPS, Arun AV, Sundari KKS, Samantha C, Ambika K. An Indigenously Designed Apparatus for Measuring Orthodontic Force. J Clin Diagn Res. 2013;7(11):2623.

21. Felicita AS. Orthodontic extrusion of Ellis Class VIII fracture of maxillary lateral incisor--The sling shot method. The Saudi dental journal. 2018;30(3):265-9.
22. Kadam A, Karjodkar F, Sansare K, Vinay V. COVID 19--Facts And Its Infection Control Measures For Dentists. academia. edu [Internet]. Available from: http://www.academia.edu/download/62843755/G190401435220200406-11820-ji073a.pdf

23. Ashwin K, Muralidharan N. Vancomycin-resistant enterococcus (VRE) vs Methicillin-resistant Staphylococcus Aureus (MRSA). Indian journal of medical [Internet]. 2015; Available from: http://search.proquest.com/openview/c8a1d0188cbf2ecf688116 $7867155 \mathrm{c} 27 / 1$ ?pq-origsite $=$ gscholar\&cbl $=226513$

24. Izzetti R, Nisi M, Gabriele M, Graziani F. COVID-19 Transmission in Dental Practice: Brief Review of Preventive Measures in Italy. J Dent Res. 2020 Apr 17;0022034520920580.

25. Yang Y, Zhou Y, Liu X, Tan J. Health services provision of 48 public tertiary dental hospitals during the COVID-19 epidemic in China. Clin Oral Investig. 2020 May 1;24(5):1861-4.

26. COVID C, Team R. Severe outcomes among patients with coronavirus disease 2019 (COVID-19) - United States, February 12--March 16, 2020. MMWR Morb Mortal Wkly Rep. 2020;69(12):343-6.

27. Shahana RY, Muralidharan NP. Efficacy of mouth rinse in maintaining oral health of patients attending orthodontic clinics. J Pharm Res [Internet]. 2016; Available from: http://www.indianjournals.com/ijor.aspx?target=ijor:rjpt\&volume $=9 \&$ issue $=11 \&$ article $=035$

28. Ahmed MA, Jouhar R, Ahmed N, Adnan S, Aftab M, Zafar MS, et al. Fear and Practice Modifications among Dentists to Combat Novel Coronavirus Disease (COVID-19) Outbreak. Int J Environ Res Public Health. 2020 Apr 19;17(8):2821.

29. Kirova DG. Dental anxiety among dental students. J of IMAB. 2011;17(2):137-9.

30. Baghizadeh Fini M. What dentists need to know about COVID-19. Oral Oncol. 2020 Jun 1;105:104741.

31. Dominiak M, Różyło-Kalinowska I, Gedrange T, Konopka T, Hadzik J, Bednarz W, et al. COVID-19 and professional dental practice. The Polish Dental Association Working Group recommendations for procedures in dental office during an increased epidemiological risk. Journal of Stomatology. 2020;73(1):1-10.

32. Renuka S, Muralidharan NP. Comparison in benefits of herbal mouthwashes with chlorhexidine mouthwash: A review. Asian J Pharm Clin Res. 2017;

33. Marickar RF, Geetha RV, Neelakantan P. Efficacy of Contemporary and Novel Intracanal Medicaments against Enterococcus Faecalis. Journal of Clinical Pediatric [Internet]. 2014; Available from: https://www.jocpd.org/doi/abs/10.17796/ jcpd.39.1.wmw9768314h56666

34. Girija SAS, Jayaseelan VP, Arumugam P. Prevalence of VIMand GIM-producing Acinetobacter baumannii from patients with severe urinary tract infection. Acta Microbiol Immunol Hung. 2018;65(4):539-50.

35. Smiline ASG, Vijayashree JP, Paramasivam A. Molecular characterization of plasmid-encoded blaTEM, blaSHV and blaCTX-M among extended spectrum $\beta$-lactamases [ESBLs] producing Acinetobacter baumannii. Br J Biomed Sci. 2018 Oct 2;75(4):200-2.

36. Priyadharsini JV, Girija ASS, Paramasivam A. An insight into the emergence of Acinetobacter baumannii as an oro-dental pathogen and its drug resistance gene profile--An in silico approach. Heliyon. 2018;4(12):e01051.

37. Vaishali M, Geetha RV. Antibacterial activity of Orange peel oil on Streptococcus mutans and Enterococcus - An In -vitro study. Research Journal of Pharmacy and Technology. 2018 Feb 28;11(2):513-4.

38. Vijayashree Priyadharsini J, Smiline Girija AS, Paramasivam A. In silico analysis of virulence genes in an emerging dental patho- 
gen A. baumannii and related species. Arch Oral Biol. 2018 Oct $1 ; 94: 93-8$.

39. Shahzan MS, Girija ASS, Priyadharsini JV. A computational study targeting the mutated L321F of ERG11 gene in C. albicans, associated with fluconazole resistance with bioactive compounds from Acacia nilotica. J Mycol Med. 2019;29(4):303-9.

40. Pratha AA, Geetha RV. Awareness on Hepatitis-B vaccination among dental students- A Questionnaire Survey. J Adv Pharm Technol Res. 2017;10(5):1360.

41. M MA, Geetha RV, Thangavelu L. Evaluation of Evaluation of anti-inflammatory action of Laurus nobilis- An in vitro study of anti-inflammatory action of Laurus nobilis-an in vitro study. IJRPS. 2019 Apr 14;10(2):1209-13.

42. As SG, J VP. CLSI based antibiogram profile and the detection of MDR and XDR strains of Acinetobacter baumannii isolated from urine samples. Med J Islam Repub Iran. 2019 Feb 8;33:3-3.

43. Paramasivam A, Priyadharsini JV, Raghunandhakumar S. N6adenosine methylation (m6A): a promising new molecular target in hypertension and cardiovascular diseases. Hypertens Res. 2019 Oct 2;43(2):153-4. 